\title{
Cu Thin Film Polyimide Heater for Nerve-Net Tactile Sensor ${ }^{+}$
}

\author{
Yusuke Suganuma ${ }^{1}$, Minoru Sasaki ${ }^{2}$, Takahiro Nakayama ${ }^{3}$, Masanori Muroyama ${ }^{4}$ and \\ Yutaka Nonomura ${ }^{1, *}$ \\ 1 Meijo University, Nagoya, Japan; 173432011@ccalumni.meijo-u.ac.jp \\ 2 Toyota Technological Institute, Nagoya, Japan; mnr-sasaki@toyota-ti.ac.jp \\ 3 Toyota Motor Corporation, Nagoya, Japan; takahiro_nakayama_aa@mail.toyota.co.jp \\ 4 Tohoku University, Sendai, Japan; muroyama@mems.mech.tohoku.ac.jp \\ * Correspondence: nonomura@meijo-u.ac.jp \\ † Presented at the Eurosensors 2017 Conference, Paris, France, 3-6 September 2017.
}

Published: 11 August 2017

\begin{abstract}
Tactile sensing is required for assistant robots. A new stacked sensor head was proposed which detects forces and thermal sensations with a nerve-net LSI chip. To measure temperatures and heat flows, the sensor head required a thin and small heater to heat up the sensor head. The features of the polyimide heater are compact, low heat capacity, low power consumption and ease of attaching it to the LSI chip. The polyimide heater consisted of Au $10 \mathrm{~nm} / \mathrm{Cu} 200 \mathrm{~nm} / \mathrm{Cr} 20 \mathrm{~nm}$ thickness layers on a polyimide film. The surface of the sensor head heated up to $60{ }^{\circ} \mathrm{C}$ by the polyimide heater with $0.3 \mathrm{~W}$. By the $\mathrm{Cu}$ thin film polyimide heater, the small stacked sensor head with the nerve-net LSI chip is enable to detect forces, temperatures, and heat flows, simultaneously.
\end{abstract}

Keywords: tactile; sensor; robot; heater; polyimide; thin film; nerve-net

\section{Introduction}

It is required for upcoming aging society to realize next generation robots such as assistant robots for housework, business work and nursing. The robots will coexist with parsons and assist them. Tactile sensors make the robots to detect contacts with parsons and things, and to grasp and hold them gently and safely. If tactile sensors detect human-like thermal sensing, they are useful for material estimation. The robots are enable to estimate materials of things, such as metals, glasses, clothes and human bodies by contact. And the robots will be able to feel health of patients. Beside an infrared thermo-camera, the tactile sensors detect temperatures of behind objects contiguously. The tactile sensors should cover whole the hands, arms and body of the robots for them to work well.

A special nerve-net LSI chip has advantages in reducing number of wiring and simultaneous measurement with various sensors [1,2] (Figures 1 and 2). The LSI chip was packaged in ceramics for good thermal conductivity and durability (Figure 3). A stacked sensor head with the LSI chip shown in Figure 4 was proposed for detecting forces and thermal sensations. The sensor head was designed to be installed in fingertips of the robots and to detect forces, temperatures, and heat flows by fingertip contacts. For accurate heat flow measurement, a heat insulator covers the sensor head except a carbon sheet top. As the heat flow detection is required to estimate materials, a heater installed into the sensor head is required to make the heat flow. For the heater of the stacked sensor head, the followings are important. The heater is compact as small as $8.5 \mathrm{~mm}$ square, low heat capacity, low power consumption, and ease to mount it into the sensor head. Conventional product heaters were not suitable for the above requirements. Compared to silicon substrate, polyimide film is superior to thermal isolation, low heat capacity and flexibility. Therefore, the thin film heater on the polyimide 
film is suitable for the sensor head. In the previous studies of polyimide heaters [3,4], gold and platinum films were used in practice. However, they were expensive and difficult to be products. We have designed and produced new heaters on a $125 \mu \mathrm{m}$ thickness polyimide film. $\mathrm{Cr}$ and $\mathrm{Cu}$ films were compared as the heater material. The electric resistances and TCRs (resistance temperature coefficient) of the heaters were measured. Heating up the sensor head to $60{ }^{\circ} \mathrm{C}$ and down to $20^{\circ} \mathrm{C}$ experiments were done with the heater. The heater materials and structures were evaluated to get the good thin film heater for the nerve-net tactile sensor $[5,6]$.

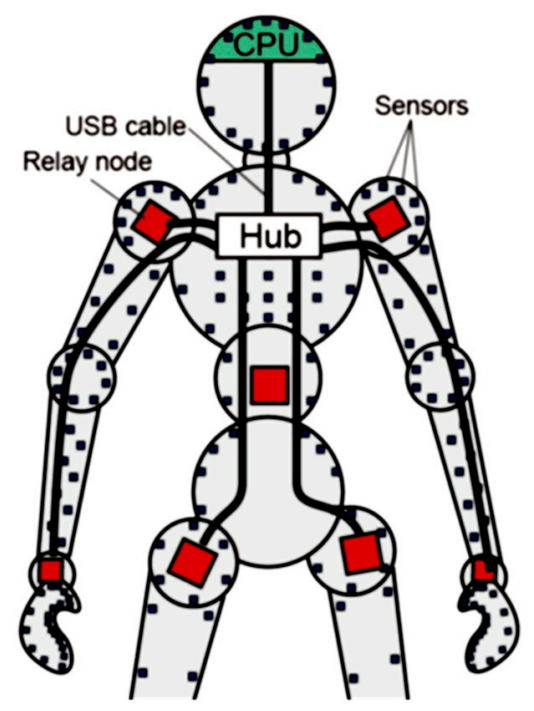

Figure 1. Image of nerve-net tactile sensing in robot.

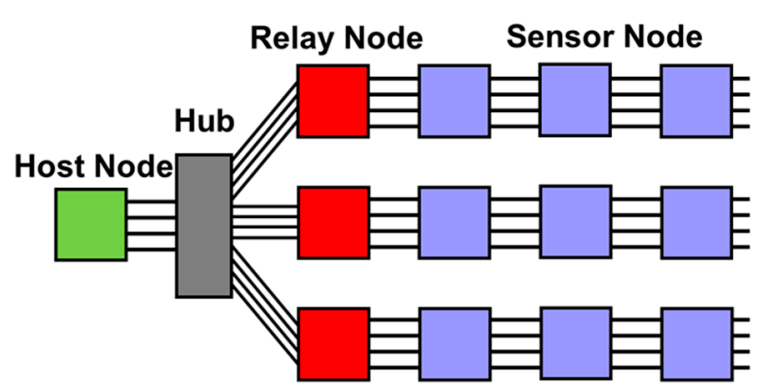

Bus: Power Supply, Ground, Signal Lines

Figure 2. Nerve-net tactile sensing systems.
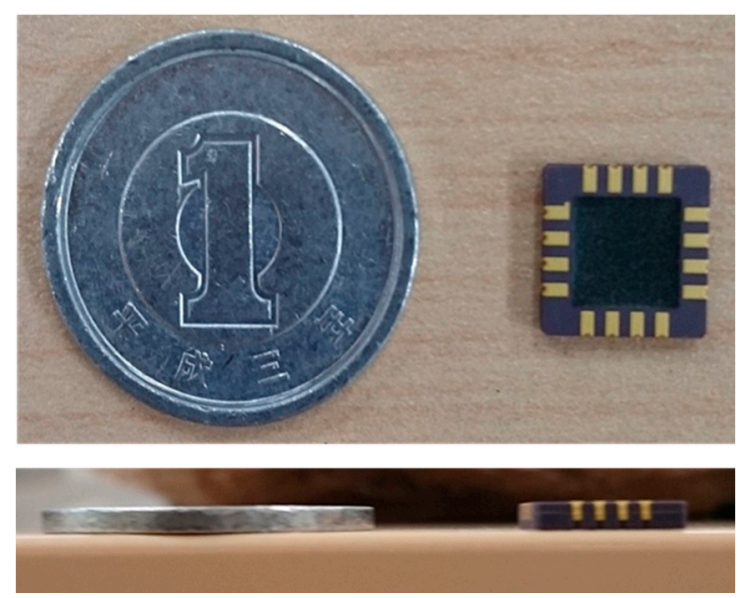

Figure 3. Nerve-net LSI chip packaged in ceramics. 


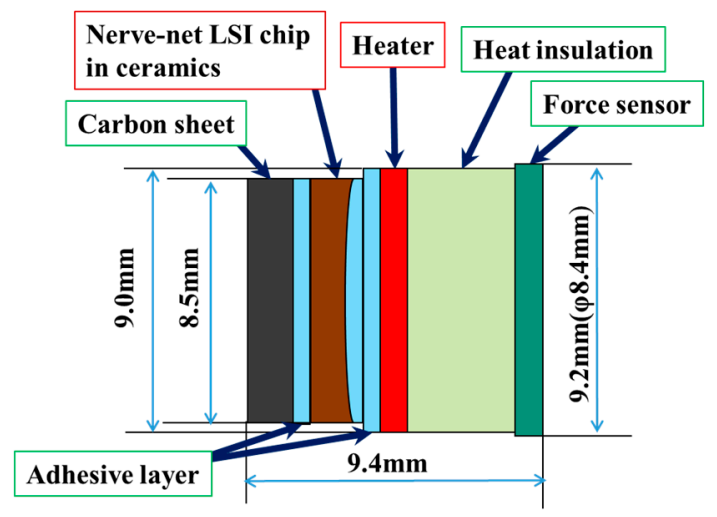

Figure 4. Structure of stacked sensor head.

\section{Design and Fabrication}

The small thin film heaters of $\mathrm{Cr}$ and $\mathrm{Cu}$ films were designed on the polyimide film for the sensor head. The required specifications of heaters are as follows.

- Area of the heater is smaller than the area of the LSI ceramic package

- Low power consumption to heat the sensor head surface up to $60^{\circ} \mathrm{C}$

- Low heat capacity to get high thermal response of the sensor head

- Easy mounting on the surface of the LSI ceramic package

The heaters were designed as $8.5 \mathrm{~mm}$ square. For low power consumption, low thermal capacity, and easy mounting, the polyimide film of $125 \mu \mathrm{m}$ in thickness was selected as the heater substrate. The polyimide film is low thermal conductivity and flexible material. $\mathrm{Cr}$ and $\mathrm{Cu}$ films were compared as the heater material. The compositions of both film resistors are shown in Table 1. Line widths of heater patterns were changed from $400 \mu \mathrm{m}$ to $800 \mu \mathrm{m}$.

A fabrication process of the heater was as follows. Firstly, the polyimide film was glued on a silicon wafer with wax and photoresist was coated. Heater patterns of the photoresist on the polyimide film were made by photolithography with a glass mask. The glass mask of the heater is shown in Figure 5. Secondly, metal layers for the resistors and electrodes were formed by a vacuum evaporation as shown in Table 1 and Figure 6. Thirdly, after the heaters on the polyimide film were detached from the silicon wafer, a polyimide tape of $55 \mu \mathrm{m}$ in thickness was pasted on the both surfaces of the heaters for protection.

Table 1. Compositions of $\mathrm{Cr}$ and $\mathrm{Cu}$ film heaters.

\begin{tabular}{cc}
\hline Style & Composition of Film \\
\hline Cr film resistor & $\mathrm{Au} 10 \mathrm{~nm} / \mathrm{Cr} 300 \mathrm{~nm} /$ Polyimide $125 \mu \mathrm{m}$ \\
$\mathrm{Cu}$ film resistor & $\mathrm{Au} 10 \mathrm{~nm} / \mathrm{Cu} 200 \mathrm{~nm} / \mathrm{Cr} 20 \mathrm{~nm} /$ Polyimide $125 \mu \mathrm{m}$ \\
Common electrode & $\mathrm{Au} 10 \mathrm{~nm} / \mathrm{Cu} 200 \mathrm{~nm} / \mathrm{Cr} 20 \mathrm{~nm}$ \\
Heater line width & $400 \mu \mathrm{m}, 600 \mu \mathrm{m}, 700 \mu \mathrm{m}, 800 \mu \mathrm{m}$ \\
\hline
\end{tabular}

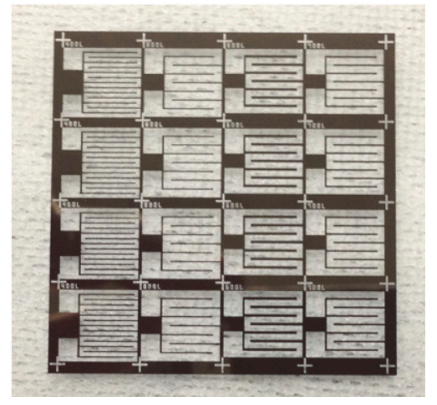

Figure 5. Glass mask of photolithography. 


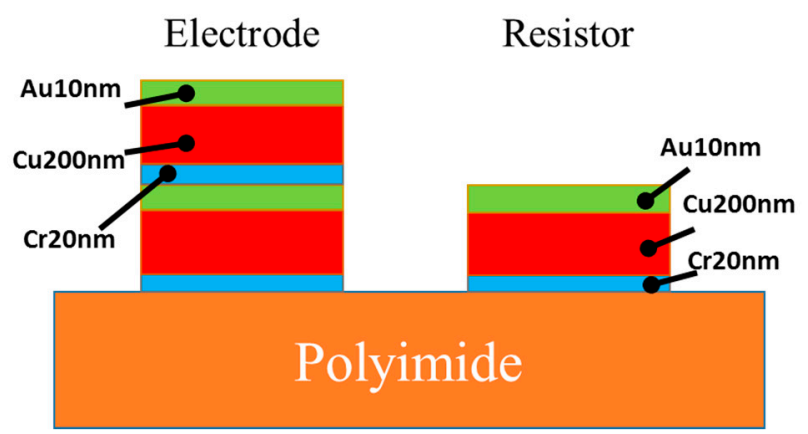

Figure 6. Metal layers on polyimide film.

\section{Results}

\subsection{Thin Film Morphology and Electric Reistance Results}

A photograph of the heater with line width $400 \mu \mathrm{m}$ is shown in Figure 7. Photomicrographs of the $\mathrm{Cr}$ and $\mathrm{Cu}$ film heater surfaces are shown in Figure 8. A lot of scratches and particle like dots were seen on the both surface films. Especially, the $\mathrm{Cr}$ film heater was damaged by scratches and particle like dots. The $\mathrm{Cr}$ film heaters had problems as electrical breaking of wire or very high resistance. The $\mathrm{Cu}$ film heaters worked well. Electric resistances of the $\mathrm{Cu}$ film heaters were presented in Table 2 in order of patterns as shown in Figure 5. The obtained electrical resistances of the Cu film heaters were about 7 times larger than calculated resistances which were estimated from a reported electrical resistivity of $\mathrm{Cu}$ bulk. By the four probes measurement, $90 \%$ of the total resistance of the heater was the resistance of the $\mathrm{Cu}$ thin film and $10 \%$ of the one was an interface resistance between the heater layer and electrode layers.

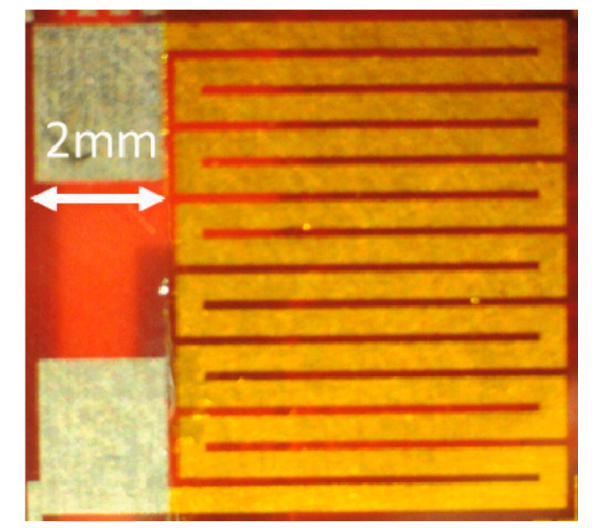

Figure 7. Photograph of the polyimide heater.

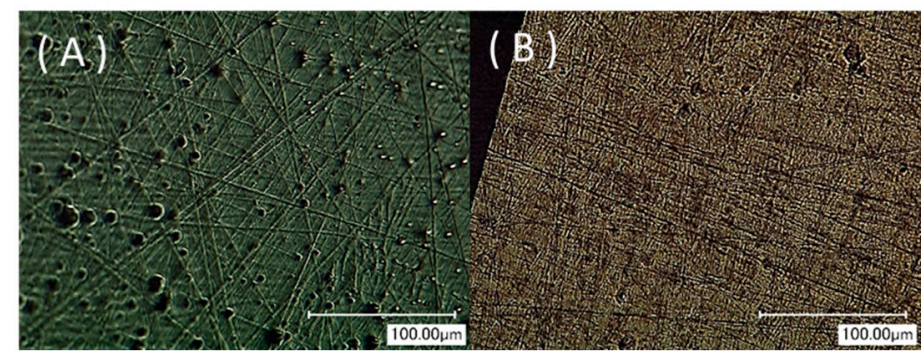

Figure 8. Photomicrographs of the $\mathrm{Cr}$ film heater (A) and the $\mathrm{Cu}$ film heater (B). 
Table 2. Resistance of the $\mathrm{Cu}$ film heater due to linewidth of heater pattern.

\begin{tabular}{|c|c|c|c|c|}
\hline Electric Resistance $[\Omega]$ & $\begin{array}{c}\text { Linewidth } \\
400 \mu \mathrm{m}\end{array}$ & $\begin{array}{c}\text { Linewidth } \\
800 \mu \mathrm{m}\end{array}$ & $\begin{array}{c}\text { Linewidth } \\
600 \mu \mathrm{m}\end{array}$ & $\begin{array}{c}\text { Linewidth } \\
700 \mu \mathrm{m}\end{array}$ \\
\hline Row 1 & 157 & 36 & 48 & 45 \\
\hline Row 2 & 136 & 34 & 44 & 42 \\
\hline Row 3 & 130 & 34 & 45 & 40 \\
\hline Row 4 & 128 & 33 & 43 & 39 \\
\hline Average Value & 138 & 34 & 45 & 41 \\
\hline Calculated Value & 18.4 & 5.1 & 6.7 & 5.8 \\
\hline Average/Calculated Ratio & $749 \%$ & $679 \%$ & $673 \%$ & $717 \%$ \\
\hline
\end{tabular}

\subsection{Heater Performance Results}

The TCRs of the $\mathrm{Cu}$ film heater of line width $800 \mu \mathrm{m}$ were measured and results were shown in Figure 9. Alumel-chromel thermocouples of $0.1 \mathrm{~mm}$ in diameter were used for temperature measurement of the heaters. It was found that the TCR of the heater was about $2.2 \times 10^{-3} /{ }^{\circ} \mathrm{C}\left(<60^{\circ} \mathrm{C}\right)$ and almost no hysteresis property was obtained. The heater was attached to the LSI ceramics package and temperatures were measured with a setup as shown in Figure 10, while an experiment of heating up and down. The $\mathrm{Cu}$ film heater was successfully achieved a required target temperature of above 60 ${ }^{\circ} \mathrm{C}$ at the sensor head surface with only $0.3 \mathrm{~W}$ as shown in Figure 11.

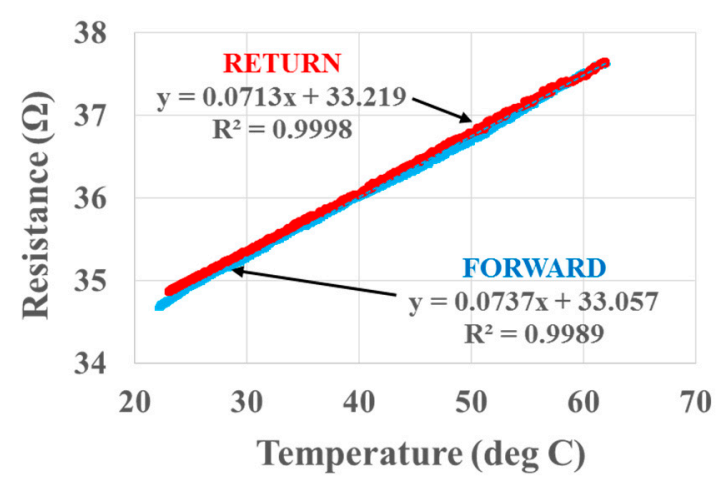

Figure 9. TCR measurement of $\mathrm{Cu}$ film heater.

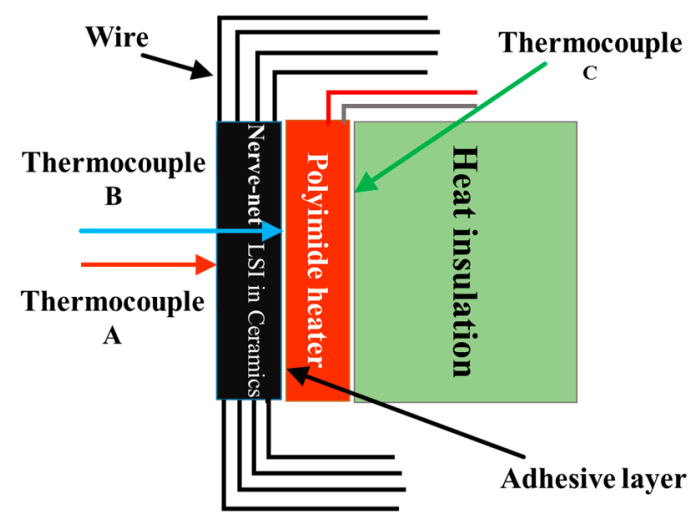

Figure 10. Heating up and down experimental setup. 


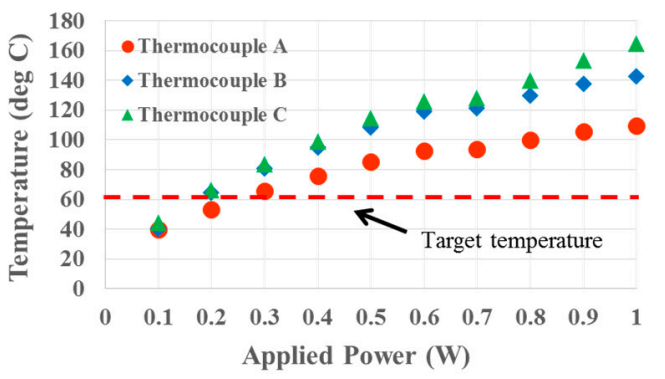

Figure 11. Heating up temperatures vs applied power.

\section{Conclusions}

It was realized that the $\mathrm{Cu}$ thin film heater on the polyimide heated up the stacked sensor head successfully. The heater was fabricated with flexible in $8.5 \mathrm{~mm}$ square and about $0.2 \mathrm{~mm}$ thickness. The obtained electrical resistances of the heater were about 7 times larger than calculated resistances which were estimated from a reported electrical resistivity of $\mathrm{Cu}$ bulk. It was found that the TCR of the heater was about $2.2 \times 10^{-3} /{ }^{\circ} \mathrm{C}\left(<60^{\circ} \mathrm{C}\right)$. The heater achieved target temperature $60^{\circ} \mathrm{C}$ at the sensor head surface with only $0.3 \mathrm{~W}$, and obtained almost no hysteresis properties. The small sensor head with the nerve-net LSI chip is enable to detect forces, temperatures, and heat flows, simultaneously. The thin film heater and small temperature sensors will be combined to create ultra-small sensor head for robot fingers and artificial robot skin.

Acknowledgments: A part of this work was supported by Toyota Technological Institute Nano Technology Hub in "Nanotechnology Platform Project" sponsored by the Ministry of Education, Culture, Sports, Science and Technology (MEXT), Japan. The present study is supported in part regarding the experiments of thermal sensing by the New Energy and Industrial Technology Development Organization (NEDO). The development of the sensor platform LSI and the integration technology was performed in R\&D Center of Excellence for Integrated Microsystems, Tohoku University under the program "Formation of Innovation Center for Fusion of Advanced Technologies" supported by Special Coordination Funds for Promoting Science and Technology with collaboration with Toyota Motor Corporation and Toyota Central R\&D Labs., Inc.

Conflicts of Interest: The founding sponsors had no role in the design of the study; in the collection, analyses, or interpretation of data; in the writing of the manuscript, and in the decision to publish the results.

\section{References}

1. Muroyama, M.; Makihata, M.; Nakano, Y.; Matsuzaki, S.; Yamada, H.; Yamaguchi, U.; Nakayama, T.; Nonomura, Y.; Fujiyoshi, M.; Tanaka, S.; et al. Development of an LSI for Tactile Sensor Systems on the Whole-Body of Robots. IEEJ Trans. Sens. Micromach. 2011, 131, 302-309.

2. Muroyama, M.; Nakayama, T.; Hata, Y.; Nonomura, Y.; Bartley, T.; Tanaka, S. A CMOS-LSI for a Sensor Network Platform of Social Robot Applications. In Proceedings of the Smart Systems Integration 2016, Munich, Germany, 9-10 March 2016; pp. 320-327.

3. Yu, S.; Wang, S.; Lu, M.; Zuo, L. A novel polyimide based micro heater with high temperature uniformity. Sens. Actuators A 2017, 257, 58-64.

4. Han, J.S.; Tan, Z.Y.; Sato, K.; Shikida, M. Thermal characterization of micro heater arrays on a polyimide film substrate for fingerprint sensing applications. J. Micromech. Microeng. 2004, 15, 282-289.

5. Yamadera, H.; Sugimoto, N.; Kageyama, Y. Preparation of MEMS Thin Film Heater by All Dry Processes and Application to GAS Sensor. IEEJ Trans. Sens. Micromach. 2011, 131, 246-250.

6. Kawato, Y.; Arimura, H.; Kudo, T. Sintering of Conductive Cu Nano Ink by Photo-sintering Process and Observation of Interface between Cu Film and PI. J. Smart Proc. 2013, 2, 173-177.

(C) 2017 by the authors. Licensee MDPI, Basel, Switzerland. This article is an open access article distributed under the terms and conditions of the Creative Commons Attribution (CC BY) license (http://creativecommons.org/licenses/by/4.0/). 